\title{
MALIGNANT TUMORS ARISING IN PATIENTS WITH CONGENITAL BONE DISEASES -INVESTIGATION BY A QUESTIONNAIRE-
}

\author{
Toyoshi Tsuruta and Yoshio OglHara \\ Department of Orthopaedic Surgery, Mie University School of Medicine, \\ Tsu 514, Japan
}

\begin{abstract}
Summary We have collected data on 111 cases of malignant tumors arising in patients with congenital, mostly hereditary bone dysplasias by means of a questionnaire.

In addition to such well-recognized associations as: chondrosarcoma in osteochondroma, sarcomas in fibrous dysplasia, chondrosarcoma in enchondromatoses, and chondrosarcoma in Maffucci syndrome, there were several combinations of tumor and bone dysplasia which have not been well documented. These combinations included three cases of osteosarcoma arising in osteogenesis imperfecta tarda, 3 cases of osteosarcoma in Rothmund-Thomson syndrome, a case of osteosarcoma and a case of chondrosarcoma in spondyloepiphyseal dysplasia tarda, 2 cases of lymphoma in metaphyseal chondrodysplasia, type McKusick, and a case of chondrosarcoma in Gardner syndrome.

While the coexistence of malignancy and bone dysplasia may in some combinations be only coincidental, in some other combinations, an interrelationship of the two conditions seems to be possible. The possibilities of such relationship are briefly discussed.
\end{abstract}

\section{INTRODUCTION}

The pathogenetic mechanisms involved in the occurrence of malignant tumors in patients with congenital, or hereditary bone diseases are so complex that they are not fully understood. Such a coexistence of malignancy in bone dysplasias had been thought to be a rare occurrence, and actual incidence has not been studied clearly as yet.

We collected data on 111 cases of malignant tumors arising in patients with bone dysplasias through a questionnaire. The purpose of this paper is to publish the data obtained and to review the literature.

Received September 16, 1983; revised version received January 27, 1984 


\section{METHODS AND RESULTS}

We sent out a questionnaire regarding the coexistence of malignant tumors in patients with bone dysplasias to 71 orthopaedic clinics of Japanese Medical Schools, and to eleven foreign authorities: Dr. P. Beighton, Cape Town, South Africa; Dr. M. Campanacci, Bologna, Italy; Dr. D.C. Dahlin, Rochester, USA; Dr. A. Giedion, Zürich, Switzerland; Dr. A.G. Huvos, New York, USA; Dr. K. Kozlowski, Sydney, Australia; Dr. P. Maroteaux, Paris, France; Dr. U. Nilsonne, Stockholm, Sweden; Dr. D.L. Rimoin, Torrance, USA; Dr. D. Sillence, Sydney, Australia; Dr. J. Spranger, Mainz, West Germany.

Answers were obtained from 38 orthopaedic clinics in Japan and all the foreign authorities; in total, data on 111 cases were collected. These appear in Tables 1 and 2 .

\section{DISCUSSION}

As shown in Tables 1 and 2, there were 74 cases of chondrosarcoma arising in solitary or multiple osteochondromas, 14 cases of osteo-, fibro- or chondrosarcoma in fibrous dysplasia, 6 cases of chrondrosarcoma in enchondromatoses, and 3 cases of chondrosarcoma in Maffucci syndrome. These associations already have been well-

Table 1. Malignant tumors in bone dysplasias.

\begin{tabular}{llrrrr}
\hline & & M & F & Total \\
\hline Osteosarcoma & Fibrous dysplasia & 4 & 1 & 3 & 8 \\
& Rothmund-Thomson syndrome & 3 & 0 & 0 & 3 \\
& Osteogenesis imperfecta tarda & 2 & 0 & 1 & 3 \\
& Spondyloepiphyseal dysplasia tarda & 1 & 0 & 0 & 1 \\
& "Dwarfism" & 2 & 1 & 0 & 3 \\
\hline Chondrosarcoma & Osteochondroma & 12 & 2 & 60 & 74 \\
& Enchondromatosis & 1 & 5 & 0 & 6 \\
& Maffucci syndrome & 2 & 1 & 0 & 3 \\
& Fibrous dysplasia & 2 & 5 & 0 & 2 \\
& Spondyloepiphyseal dysplasia tarda & 1 & 0 & 0 & 1 \\
\hline Fibrosarcoma & Gardner syndrome & 0 & 0 & 1 & 1 \\
\hline Lymphoma & Fibrous dysplasia & 2 & 1 & 1 & 4 \\
\hline
\end{tabular}


Table 2. Bone diseases associated with malignant tumors.

\begin{tabular}{lc}
\hline Osteochondroma + Chondrosarcoma & 74 \\
Enchondromatosis + Chondrosarcoma & 6 \\
Maffucci syndrome +Chondrosarcoma & 3 \\
Fibrous dysplasia + Osteosarcoma & 8 \\
+Chondrosarcoma & 2 \\
+Fibrosarcoma & 4 \\
Rothmund-Thomson syndrome+Osteosarcoma & 3 \\
Osteogenesis imperfecta+Osteosarcoma & 3 \\
Spondyloepiphyseal dysplasia tarda +Osteosarcoma & 1 \\
Tetaphyseal chondrodysplasia (type McKusick)+Lymphoma & 2 \\
Gardner syndrome+Chondrosarcoma & 1 \\
"Dwarfism" +Osteosarcoma & 3 \\
\hline Total & 111 \\
\hline
\end{tabular}

recognized; the incidence of chondrosarcoma in osteochondroma is presumed to be $5-25 \%$ (Huvos, 1979); chondrosarcoma in enchondromatoses 32-50\%; chondrosarcoma in Maffucci syndrome 15\% (Lewis and Ketcham, 1973); sarcomas in fibrous dysplasia 3.3\% (Campanacci et al., 1979).

In addition to the well-known associations mentioned above, there were several combinations of malignant tumor and bone dysplasia which have not been well-recognized as yet. Our discussion will be focused mainly on these relatively rare associations.

\section{1) Osteosarcoma arising in osteogenesis imperfecta tarda}

Osteogenesis imperfecta tarda is a relatively uncommon bone dysplasia inherited as autosomal dominant transmission. The clinical features are characterized by abnormal bone fragility, blue sclera and deafness.

Three cases listed in Tables 1 and 2 were informed by Prof. Spranger and these consisted of the cases reported by Lasson et al. (1978) and Rutkowski et al. (1979), and one case from Dr. Dahlin. From the orthopaedic clinics in Japan, no case was cited.

The first case of osteosarcoma occurring in osteogenesis imperfecta tarda was reported by Jewell et al. in 1940. Since then, several cases have been reported in the literature (Roschlau, 1962; Klenerman et al., 1967; Lasson et al., 1978; Rutkowski et al., 1979; Reid and Hubbard, 1979). Rutkowski reported a 15-year-old boy and stated that osteosarcoma was extremely rare in association with osteogenesis imperfecta tarda, and that only 8 cases have been reported in the literature. 
The signinicance of the association of both conditions has not been fully understood. According to Solomons (1976), "cancer resistance" in patients with osteogenesis imperfecta tarda had been previously reported from epidemiological studies. Klenerman et al. (1967) reported two girls with osteosarcoma in osteogenesis imperfecta tarda and suggested that the tumors arose spontaneously and were not related to the underlying bone disorder. Lasson et al. (1978) also stated that both disorders were rare, so the question of a more than coincidental occurrence cannot be answered. They suggested that the number of osteosarcoma cases might be much higher if multiple fractures and/or metallic foreign bodies for the treatment of fractures played an etiologic role in tumor generation in patients with osteogenesis imperfecta tarda. These concepts, however, have not been established. Furthermore, in their answers to our questionnaire, Prof. Beighton and Prof. Sillence mentioned that among 300 and 250 patients respectively with osteogenesis imperfecta tarda, they personally did not observe even a single case of malignant tumor. Thus, it seems reasonable to assume that the coexistence of both diseases may be extremely rare.

Hyperplastic callus formation occurring in osteogenesis imperfecta tarda has been well-recognized. Clinical pictures of this condition can resemble osteosarcoma, and from a clinical viewpoint alone, the two sometimes indistinguishable. To avoid the confusion, adequate biopsy should be advocated.

\section{2) Osteosarcoma arising in Rothmund-Thomson syndrome}

Rothmund-Thomson syndrome, or poikiloderma congenitale, is a rare autosomal recessive disorder. It was first described by Rothmund in 1868, and later by Thomson in 1923. The syndrome is characterized by peculiar atrophic skin changes, erythema, teleangiectasia, sunlight sensitivity, short stature, sparse eyebrows and lashes with or without cataracts, defective bone development most evident in short tubular bones, and defective dentition (Hall et al., 1980).

Two of the three cases listed in Tables 1 and 2 are Japanese boys, and the remaining case, a 13-year-old boy was reported from Australia (Kozlowski et al., 1980). In addition, there are three cases reported in the literature: Roschlau (1962) described a boy with Rothmund-Thomson syndrome who developed an osteosarcoma of the right femur and died of lung metastases; Dick et al. (1982) reported a 5-year-old girl who developed an osteosarcoma of the left tibia; Davies (1982) described a adult patient who developed an osteosarcoma of the left humerus.

Because Rothmund-Thomson syndrome is a very rare disease and osteosarcoma is not a common tumor, six cases-three cases collected through the questionnaire, and three cases in the literature--may suggest some interrelationship between the two conditions. Moreover, taking into account the fact that in Werner syndrome-distinct but apparently related to Rothmund-Thomson syndrome-six of 62 cases had malignant tumors (Perloff and Rhelps, 1958), the possibility that two conditions are related in their underlying mechanism can not be excluded. Although not convincingly proven, Dick et al. (1982) suggested that the possible link of the association which 
has not been elucidated by current technique, might be through a subtle defect in repairing the damaged DNA.

\section{3) Osteo- and chondrosarcoma arising in spondyloepiphyseal dysplasia tarda}

Spondyloepiphyseal dysplasia tarda (SED tarda) is a rare inherited bone dysplasia with a likely prevalence of around 7.7 per million (Branford et al., 1982). Although several types have been reported in the literature, the X-linked recessive form appears to be most frequent (Bannerman et al., 1971). It was first described in three affected brothers by Nilsonne in 1927. The term spondyloepiphyseal dysplasia tarda was coined by Maroteaux et al., 1957.

The clinical features of this bone dysplasia are characterized by short stature due to impaired growth of the spine, which is first evident in childhood between 5-14 years. Radiologically platyspondylia with central humping, dysplastic changes in femoral heads and neck and minor changes in other bones can be observed.

In Tables 1 and 2, there are two cases of SED tarda with malignant tumors. The case with osteosarcoma is our own, the other is a case with chondrosarcoma received in an answer from a Japanese orthopaedic clinic.

In reviewing the literature regarding SED tarda, we could not find any case associated with malignant tumor other than the patient reported by Branford et al. (1982). That patient had SED tarda and also poikiloderma atrophicans vasculare progressing to lymphocytic lymphoma. The lymphoma seemed to be related to the skin changes and not to the bone dysplasia.

At present, because of the small number of patients reported in the literature, the interrelationship between SED tarda and sarcoma is uncertain.

\section{4) Lymphoma arising in metaphyseal chondrodysplasia, type McKusick}

Metaphyseal chondrodysplasia, type McKusick, or cartilage-hair hypoplasia, is a rare autosomal recessively inherited bone dysplasia. It was first described by McKusick (1964) based on 77 affected individuals in Old Order Amish.

As shown in Tables 1 and 2, two cases of lymphoma arising in patients with metaphyseal chondrodysplasia, type McKusick, were collected. One is a case of histiocytic lymphoma in a 35-year-old female in answer from Dr. Turack-Garcia (Dr. Rimoin's case), and the other is our own case of malignant lymphoma originating from the thyroid gland in a 7-year-old Japanese girl.

Clinical features of metaphyseal chondrodysplasia, type McKusick, include shortlimbed dwarfism, metaphyseal chondrodysplasia and abnormally fine, blonde, sparse hair. Associated abnormalities include aganglionic megacolon, malabsorption, neutropenia and lymphopenia. It was noted that the affected individuals are unusually susceptible to infections with varicella and vaccinia viruses, and such a severe response to these viral infections suggests some kind of immune deficiency in this syndrome. In fact, Lux et al. (1970) reported that some children with this disorder have a distinct form of cellular immune defect. Vilolainen et al. (1978) stated that a defect in cellular 
immunity is an integral part of this bone dysplasia. Wilson et al. (1978) also reported that deficiency of both cellular and antigen function have been demonstrated in this bone dysplasia.

Kersy et al. (1974) suggested that the risk of death from malignancy in children with primary immunodeficiency disease appeared to be about 100 times greater than that of the general population, and that the increased risk of development of malignancy might be largely due to the intrinsic lymphoid abnormalities resulting in greater than normal malignant transformation of lymphoid cells. They also suggested that chronic antigenic stimulation possibly with oncogenic viruses might also account for the high rate of lymphoid malignancies. Thus, in view of the above-mentioned considerations, we feel that a relationship between lymphoma and metaphyseal chondrodysplasia, type McKusick, may be quite possible.

\section{5) Chondrosarcoma arising in Gardner syndrome}

Gardner syndrome was first described by Gardner et al. during the years 19511953. The clinical features are characterized by the triad consisting of polyposis of the colon, osteomas, and connective tissue tumors. It is transmitted by autosomal dominant inheritance.

The one and only case listed in Tables 1 and 2 was chondrosarcoma of the hyoid. This case was the answer from Dr. Dahlin.

In patients with Gardner syndrome, a number of cases with desmoids but few cases of fibrosarcoma have been reported (Rödl, 1979). To our best knowledge, however, no case with chondrosarcoma has been described. Therefore, whether or not the coexistence of chondrosarcoma in Gardner syndrome is more than coincidental is as yet uncertain.

In conclusion, while the coexistence of some nialignant tumors in congenital bone disease might be merely coincidental, in some combinations there may be a potential interrelationship between the two conditions. The full answer to the question awaits further investigation, bat we believe a first step in the resolution would be to collect data on as many such cases as possible.

Acknowledgenent The authors would like to thank Drs. P. Beighton, M. Campanacci, D.C. Dahlin, A. Giedion, A.G. Huwos, K. Kozlowski, P. Maroteaux, U. Nilsonne, D.L. Rimoin, D. Sillence and J. Spranger for helpful informations.

\section{REFERENCES}

Bannerman, R.M., Ingall, G.B., and Mohn, J.F. 1971. X-linked spondyloepiphyseal dysplasia tarda: clinical and linkage data. J. Med. Genet. 8: 291-301.

Branford, W.A., Beveridge, G.W., and Wynne-Davies, R. 1982. Two first cousins with spondyloepiphyseal dysplasia tarda (X-linked recessive form), one also with poikiloderma atrophicans vasculare progressing to lymphocytic lymphoma. J. Med. Genet, 19: 210-213.

Campanacci, P., Bertoni, F., and Capanna, R. 1979. Malignant degeneration in fibrous dysplasia (presentation of 6 cases and review of the literature). Ital. J. Orthop. Traumatol. 5: 373-381.

Davies, M.G. 1982. Rothmund-Thomson syndrome and malignancy. Clin. Exp. Dermatol. $7: 455$. 
Dick, D.C., Morley, W.N., and Watson, J.T. 1982. Rothmund-Thomson syndrome and osteogenic sarcoma. Clin. Exp. Dermatol. 7: 119-123.

Hall, J.G., Pagon, R.A., and Wilson, K.M. 1980, Rothmund-Thomson syndrome with severe dwarfism. Am. J. Dis. Child. 134: 165-167.

Huvos, A.G. 1979. Bone Tumors, Diagnosis, Treatment and Prognosis, 1st Ed., Saunders, Philadelphia, p. 152.

Kersey, J.H., Spector, B.D., and Good, R.A. 1974. Cancer in children with primary immunodeficiency diseases. J. Pediatr. 84: 263-264.

Klenerman, L., Ockenden, B.G., and Townsend, A.C. 1967. Osteosarcoma occurring in osteogenesis imperfecta. Report of two cases. J. Bone Joint Surg. 49B: 314-323.

Kozlowski, K., Scougall, J.S., and Oates, R.K. 1980. Osteosarcoma in a boy with Rothmund-Thomson syndrome. Pediatr. Radiol. 10: 42-45.

Lasson, U., Harms, D., and Wiedemann, H.-R. 1978. Osteogenic sarcoma complicating osteogenesis imperfecta tarda. Eur. J. Pediatr. 129: 215-218.

Lewis, R.J., and Ketcham, A.S. 1973. Maffucci syndrome: functional and neoplastic significance. J. Bone Joint Surg. 55A: 1465-1479.

Lux, S.E., Johnston, R.B., August, C.B., Say, B., Penchaszadeh, V.B., Rosen, E.S., and McKusick, V.A. 1970. Chronic neutropenia and abnormal cellular immunity in cartilage-hair hypoplasia. N. Engl. J. Med. 282: 231-236.

McKusick, V.A. 1964. Metaphyseal dysostosis and thin hair: A "new" recessively inherited syndrome. Lancet I: 832-833.

Perloff, J.K., and Phelps, E.T. 1958. A review of Werner's syndrome with a report of the second autopsied case. Ann. Intern. Med. 48: 1205-1220.

Reid, R.S., and Hubbard, J.D. 1979. Osteosarcoma arising in osteogenesis imperfecta. Pediatr. Radiol. 8: 110-112.

Rödl, W. 1979. Das Gardner-Syndrom-drei eigene Beobachtung mit unterschiedlicher Organmanifestation. Fortschr. Röntgestr. 130: 558-563.

Roschlau, G. 1962. Rothmund-Syndrom kombiniert mit Osteogenesis imperfecta tarda und Sarkom des Obserschenkels. Zschr. Kinderheilkd. 86: 289-298.

Rutkowski, R., Resnick, P., and McMaster, J.H. 1979. Osteosarcoma occurring in osteogenesis imperfecta. A case report. J. Bone Joint Surg. 61A: 606-608.

Solomons, C.C. 1976. Osteogenesis imperfecta. Biochemical defects. Clin. Orthop. 116: 259.

Virolainen, M., Savilahti, E., Kaitila, A., and Perheentupa, J. 1978. Cellular and humoral immunity in cartilage-hair hypoplasia. Pediatr. Res. 12:961-966.

Wilson, W.G., Aylsworth, A.S., Folds, J.D., and Whisnant, J.K. 1978. Cartilage-hair hypoplasia (metaphyseal chondrodysplasia, type McKusick) with combined immune deficiency: Variable expression and development of immunologic function in sibs. Birth Defects: Original Article Series, XIV (6A): 117-129. 